\title{
A Rare Case of Primary Uterine Non-Hodgkins's Lymphoma with Involvement of Right Ovary: Staging with 18F FDG PET/CT and lodinated Contrast CT
}

\begin{abstract}
Primary uterine non-Hodgkin's lymphomas are extremely rare, and consequently, imaging findings of this disease have rarely been reported in the literature. We present fluorine-18-fluorodeoxyglucose $\left({ }^{18}[\mathrm{~F}] \mathrm{FDG}\right)$ positron emission tomography/computerized tomography (CT) and iodinated contrast $\mathrm{CT}$ findings in a young patient with primary uterine non-Hodgkin's B-cell lymphoma with right ovary involvement.
\end{abstract}

Keywords: Extranodal lymphoma, non-Hodgkin's lymphoma, positron emission tomography/computerized tomography, uterine lymphoma

\section{Introduction}

Primary uterine non-Hodgkin's lymphomas are extremely rare $(0.5 \%$ of all extranodal non-Hodgkin's lymphomas); ${ }^{[1]}$ the presentation of this disease lacks specific clinical symptoms and it is often difficult to distinguish from other uterine neoplasms. Due to its low incidence, diagnosis is often delayed and treatment is not defined. Based on the literature published to date, localized treatment with radiation therapy or surgery combined with chemotherapy is reported to improve outcome, with 10-year disease-free survival. ${ }^{[2,3]}$ Diffuse large B-cell subtype is the most common variant in the literature. ${ }^{[4]}$ The uterine cervix is the most common site of primary uterine non-Hodgkin's lymphomas..$^{[5]}$

To the best of our knowledge, few imaging reports are available in the literature on this disease. In this paper, we present fluorine-18-fluorodeoxyglucose $\left({ }^{18}[\mathrm{~F}] \mathrm{FDG}\right)$ positron emission tomography (PET)/computerized tomography (CT) and iodinated contrast CT findings in a young patient with primary uterine non-Hodgkin's B-cell lymphoma.

\section{Case Report}

A 28-year-old woman (the authors certify that they have obtained all appropriate patient consent forms, in the form the patient has given her consent for her images and

This is an open access journal, and articles are distributed under the terms of the Creative Commons Attribution-NonCommercial-ShareAlike 4.0 License, which allows others to remix, tweak, and build upon the work non-commercially, as long as appropriate credit is given and the new creations are licensed under the identical terms.

For reprints contact: reprints@medknow.com other clinical information to be reported in the journal), with a previous history of melanoma of the back, came to our hospital for irregular menstrual cycles in February 2018. Laboratory tests showed decreased lymphocytes count $(9.3 \%$; range $20 \%-45 \%)$. Ultrasounds examinations revealed a big solid mass in the cervix with an inhomogeneous echogenicity and no evidence of significant ovarian alterations [Figure 1]. After a cervix biopsy, the histological examination showed that the tumor cells were positive for LCA, CD20, CD3, CD10, bc16 and negative for s100 protein, CD56, smooth muscle actin, desmin, chromogranin, synaptophysin, HMB45, CD99, cyclin D1, and CD30; Ki-67 staining showed that the proportion of the positive tumor cells was about $70 \%$. These findings were consistent with a diagnosis of primary uterine high-grade non-Hodgkin's B-cell lymphoma.

For staging purposes, PET/CT with ${ }^{18}[\mathrm{~F}]$ FDG $(250 \mathrm{MBq}$ ev $)$ and iodinate contrast (iobitridol; volume: $100 \mathrm{~mL}$ and flow rate: $2.5 \mathrm{~mL} / \mathrm{s}$ ) was performed. The images showed an uterine mass extended from fundus to cervix (longitudinal diameter $58 \mathrm{~mm}$ and axial diameter $64 \mathrm{~mm}$ ), with a high uptake of ${ }^{18}[\mathrm{~F}]$ FDG (maximum standardized uptake value $\left.\left[\mathrm{SUV}_{\max }\right]\right) 16.2 \mathrm{~g} /$ $\mathrm{ml} \mathrm{bw}$, metabolic volume tumor $17 \mathrm{~cm}^{3}$ ) [Figure 2]. The mass also showed contrast

\footnotetext{
How to cite this article: Lamacchia F, Cimini $A$, Ferrari D, Chiaravalloti A, Schillaci O, Floris R. A rare case of primary uterine non-hodgkins's lymphoma with involvement of right ovary: Staging with $18 \mathrm{~F}$ FDG PET/CT and lodinated Contrast CT. Indian J Nucl Med 2019;34:60-1.
}

\section{Feliciana \\ Lamacchia ${ }^{1}$, Andrea Cimini ${ }^{1}$, Donatella Ferrari ${ }^{1}$, Agostino Chiaravalloti ${ }^{1,2}$, Orazio Schillaci ${ }^{1,2}$, Roberto Floris ${ }^{1}$}

${ }^{l}$ Department of Biomedicine and Prevention University of Rome "Tor Vergata", ${ }^{2}$ Department of Nuclear Medicine IRCCS, Neuromed, Pozzilli, Italy

Address for correspondence: Dr. Feliciana Lamacchia, Unversity of Rome "Tor Vergata”, Viale Oxford 81, 00133, Rome, Italy.

E-mail: lamacchia.feliciana@ gmail.com

Access this article online

Website: www.ijnm.in

DOI: 10.4103/ijnm.IJNM_116_18

Quick Response Code:

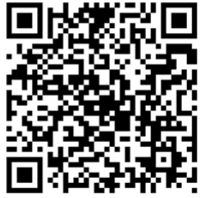




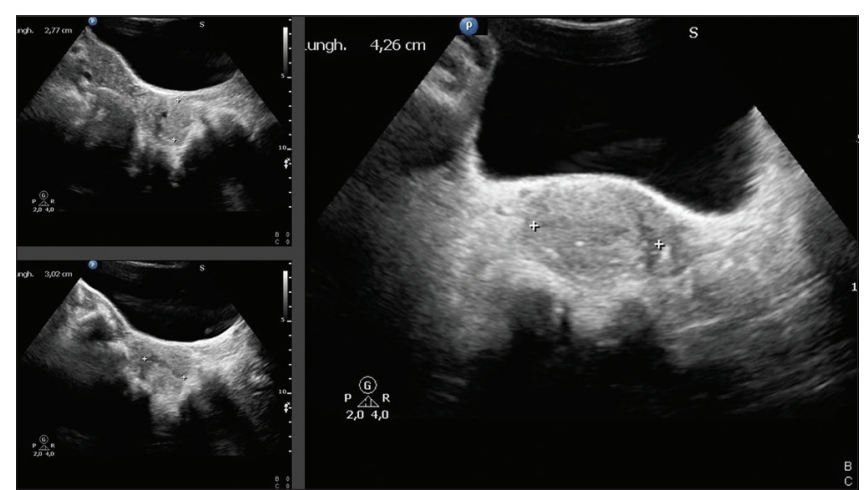

Figure 1: Pelvic ultrasound showing a big uterine mass with inhomogeneous echogenicity

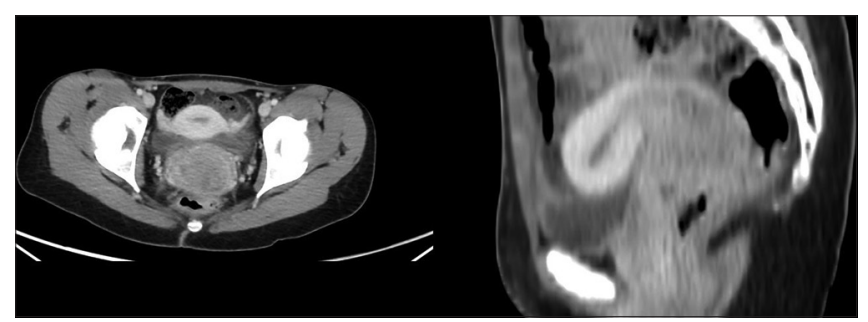

Figure 3: Axial and sagittal computerized tomography scan showing contrast enhancement in the uterine mass

enhancement after iodinate contrast administration [Figure 3]. Moreover, the right ovary presented a moderate enlargement $(40 \mathrm{~mm} \times 23 \mathrm{~mm})$ and a big uptake of the radiopharmaceutical $\left(\mathrm{SUV}_{\max } 7.7 \mathrm{~g} / \mathrm{ml} \mathrm{bw}\right)$ [Figure 4]. Compression of the right ureter at the bladder outlet was observed. Nonpathological pelvic and abdominal lymph nodes were noticed. In March 2018, the patient underwent laparoscopic right ovarian biopsy that showed the involvement of non-Hodgkin's B-cell lymphoma in the ovary.

\section{Discussion}

Primary uterine non-Hodgkin's lymphomas, and consequently, the imaging of this malignant disease are extremely rare. PET/CT combines the functional information of PET with the structural details of the CT. PET/CT scan confirmed the presence of a voluminous uterine mass with high glucose metabolism, proving the presence of pathology with a high-rate malignancy and allowing a better definition of the extension and the size of the lesion. Metabolic and morphological imaging also showed an involvement of the right ovary with compression of the ipsilateral ureter and absence of pathological lymph nodes, thus leading to correct staging and an appropriate planning of therapy.

\section{Declaration of patient consent}

The authors certify that they have obtained all appropriate patient consent forms. In the form the patient(s) has/have given his/her/their consent for his/her/their images and other clinical information to be reported in the journal. The patients understand that their names and initials will not

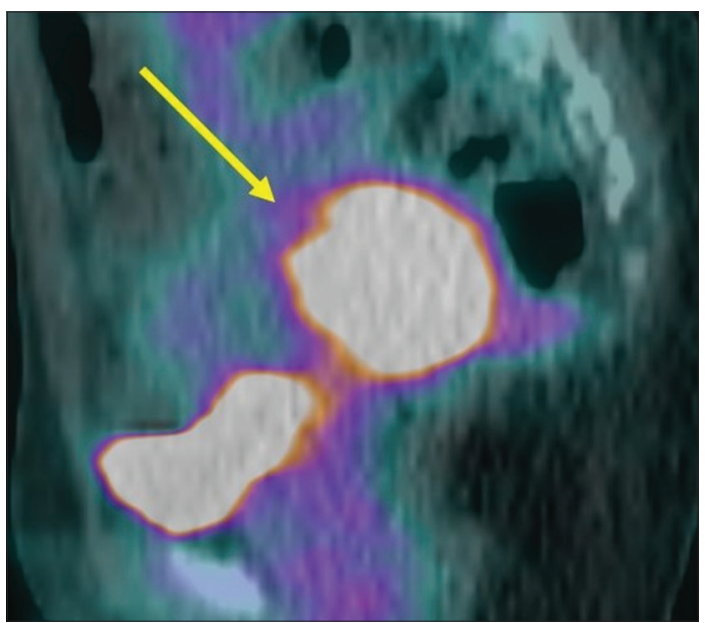

Figure 2: Positron emission tomography/computerized tomography sagittal scan showing a big hypermetabolic uterine mass (yellow arrow) with maximum standardized uptake value $16.2 \mathrm{~g} / \mathrm{ml}$ bw

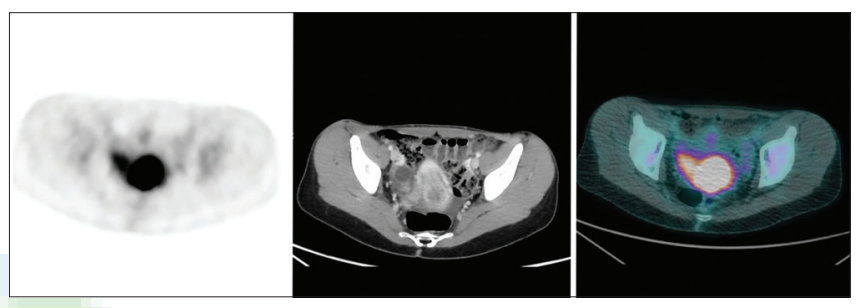

Figure 4: Positron emission tomography, computerized tomography with iodinated contrast and positron emission tomography/computerized tomography axial scans showing the involvement of the right ovary (orange arrows)

be published and due efforts will be made to conceal their identity, but anonymity cannot be guaranteed.

\section{Financial support and sponsorship}

Nil.

\section{Conflicts of interest}

There are no conflicts of interest.

\section{References}

1. Sugimoto KJ, Imai H, Shimada A, Wakabayashi M, Sekiguchi Y, Nakamura N, et al. Diffuse large B-cell lymphoma of the uterus suspected of having transformed from a marginal zone B-cell lymphoma harboring trisomy 18: A case report and review of the literature. Int J Clin Exp Pathol 2013;6:2979-88.

2. Yamamoto Y, Chaki O, Nakayama M. Two cases of Non-Hodgkin's lymphoma involving the uterus. Gynecol Obstet (Sunnyvale) 2014;4:213.

3. Horning SJ, Weller E, Kim K, Earle JD, O'Connell MJ, Habermann TM, et al. Chemotherapy with or without radiotherapy in limited-stage diffuse aggressive non-Hodgkin's lymphoma: Eastern cooperative oncology group study 1484. J Clin Oncol 2004;22:3032-8.

4. Patro MK, Bal AK, Santosh T, Mishra B. Primary non-Hodgkin's lymphoma of diffuse large B-cell phenotype [DLBCL] of uterine corpus: A rare case report with brief review of the literature. J Obstet Gynaecol India 2016;66:675-8.

5. Jeong D, Jeong Y, Jeon S, Cho HD, Bae DH, Kim CJ. A case of primary non-Hodgkin's lymphoma of the myometrium with involvement of bilateral ovaries. Basic Appl Pathol 2009;2:40-3. 